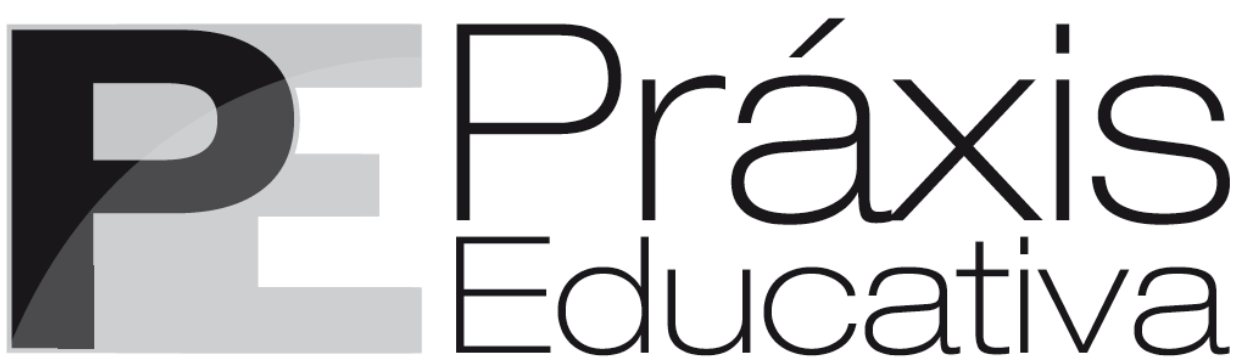

ISSN 1809-4309 (Versão online) DOI: 10.5212/PraxEduc.v.11i2.0007

\title{
O papel das affordances na aquisição da Libras como segunda língua*
}

\section{The role of affordances in Libras acquisition as second language}

\section{El papel de las affordances en la adquisición de Libras como segunda}

lengua

\author{
Jéssica Puhl ${ }^{* *}$ \\ Elaine Ferreira do Vale Borges ${ }^{* * *}$
}

Resumo: A Libras é uma língua viso-espacial utilizada pela comunidade surda brasileira. Seguindo os princípios da espacialidade e da visão, o usuário da língua de sinais recorre com mais facilidade aos estímulos do meio do que o usuário da língua oral-auditiva. Assim, parte-se da hipótese de que as affordances (propriedades do ambiente que viabilizam ações psicologicamente possíveis) seriam um elemento facilitador no processo de aquisição da Libras. Utilizando-se da pesquisa narrativa e interpretativista de natureza qualitativa, discute-se o papel das affordances no ciclo de percepção, interpretação e ação de uma ouvinte na aquisição de Libras como segunda língua. Resultados apontam que os sinais icônicos podem ser considerados importantes affordances nos estágios iniciais da aquisição. Constata-se, ainda, a importância da permanência no nicho em que naturalmente se usa a Libras para a evolução nesse processo.

Palavras-chave: Affordances. Aquisição de segunda língua. Língua brasileira de sinais.

Abstract: Libras is a visual-spatial language used by the Brazilian deaf community. Following the principles of spatiality and vision, the user of the sign language resorts more easily to stimuli from the environment than the user of the oral language. Thus, the hypothesis of this research is that the affordances (environmental properties that enable psychologically possible actions) would be a facilitator element in the process of Libras acquisition. In this paper we use the narrative and interpretive-qualitative research to discuss the role of affordances in the listener perception, interpretation and action cycle in Libras acquisition as second language. Results show that the Libras' iconic signs can be considered important affordances in the early stages of the acquisition. It is also observed the importance of the permanence in the niche where Libras is used for the sign language development.

Keywords: Affordances. Second language acquisition. Brazilian sign language.

Resumen: La Libras es una lengua viso-espacial utilizada por la comunidad sorda brasileña. Siguiendo los principios de la espacialidad y visión, el usuario de la lengua de señas recurre con más facilidad a los

\footnotetext{
* Este artigo foi produzido a partir de pesquisa desenvolvida pelo Programa Institucional de Bolsa de Iniciação Científica (PIBIC) 2014-2015, com bolsa da Universidade Estadual de Ponta Grossa (UEPG).

** Universidade Estadual de Ponta Grossa. E-mail: <jessicapuhl95@gmail.com>.

Professora da Universidade Estadual de Ponta Grossa. E-mail: <elainefvb@gmail.com; elainefvb@uepg.br>.
} 
estímulos del medio que el usuario de la lengua oral-auditiva. Así, se parte de la hipótesis que las affordances (propiedades del ambiente que viabilizan acciones psicológicamente posibles) serían un elemento facilitador en el proceso de adquisición de la Libras. Utilizando la pesquisa narrativa e interpretativa de naturaleza cualitativa, se discute el papel de las affordances en el ciclo de percepción, interpretación y acción de una oyente en la adquisición de Libras como segunda lengua. Resultados apuntan que las señales icónicas pueden ser consideradas importantes affordances en los estados iniciales de la adquisición. Se verifica, todavía, la importancia de la permanencia en el nicho en que naturalmente se usa Libras para la evolución en ese proceso.

Palabras clave: Affordances. Adquisición de segunda lengua. Lengua brasileña de señas.

\section{Introdução}

Este artigo é resultado de pesquisa desenvolvida pelo Programa Institucional de Bolsa de Iniciação Científica (PIBIC), 2014-2015, da Universidade Estadual de Ponta Grossa (UEPG), no contexto da investigação e da reflexão do processo de primeiro contato e estágio inicial da aquisição da Língua brasileira de sinais (Libras) como segunda língua (L2) por uma aprendiza ouvinte, cuja língua materna (L1) é a língua portuguesa.

A Libras, de natureza viso-espacial, é a L1 da comunidade surda brasileira, assim como a língua portuguesa do Brasil ou língua brasileira (ORLANDI, 2005), oral-auditiva, é a L1 da comunidade ouvinte. Similar a qualquer outra língua, as línguas de sinais possuem características próprias marcadas principalmente pela utilização da espacialidade e da visão e não derivam (como podem pensar algumas pessoas) das línguas orais, tendo em vista que "[...] fluíram de uma necessidade natural de comunicação entre as pessoas que não utilizam o canal auditivo-oral, mas o canal espaço-visual como modalidade linguística" (QUADROS, 1997 apud STREIECHEN, 2013 , p. 27). Nesse panorama, a Libras possui também suas próprias regras e formalidades em relação aos níveis linguísticos (recorrente à gramática), subsidiadas pelos parâmetros linguísticos da Libras. A compreensão do componente gramatical da Libras ocorre pelo entendimento da formação frasal do surdo transmitida e receptada por meio da percepção viso-espacial (STREIECHEN, 2013). Em sua essência, como também ocorre nas línguas orais-auditivas, as línguas de sinais expressam conceitos concretos e abstratos e compartilham do princípio da arbitrariedade do signo saussuriano. Assim, as línguas de sinais constituem-se tanto por sinais icônicos (como, por exemplo, nas palavras "telefone", "caneta", "árvore" etc.) que reproduzem a imagem do seu referente, quanto por sinais arbitrários (como nos vocábulos "mês", "educação", "profissional" etc.) que não fazem menção ao que foi sinalizado, ou seja, não se assemelham à realidade que representam.

Tendo em vista o aspecto viso-espacial como o canal que permite a expressividade e/ou manifestação linguístico-comunicativa das línguas de sinais, esta pesquisa visou diagnosticar o papel das affordances (GIBSON, 1977; VAN LIER, 2000, 2002, 2004; PAIVA, 2010) como facilitador (ou não) no processo de aquisição da Libras, como L2, por uma aprendiza ouvinte, cuja L1 é a língua brasileira.

No campo da psicologia ecológica, James Gibson desenvolveu o conceito de affordance como propriedades do ambiente consideradas pelo observador em uma dada relação cuja percepção conduz a ações psicologicamente possíveis. Por outro lado, van Lier (2000, 2002) enfatizou o papel das affordances no processo de ensino e de aquisição de segunda língua, destacando suas principais características como relações, possibilidades, oportunidades, imediatismos e interações. $\mathrm{Na}$ visão de van Lier, affordance refere-se ao que está disponível à pessoa. Assim, a ação em potencial surge quando interagimos com o mundo físico e social e,

Práxis Educativa, Ponta Grossa, v. 11, n. 2, p. 434-448, maio/ago. 2016 Disponível em: <http://www.revistas2.uepg.br/index.php/praxiseducativa $>$ 
como nas práticas sociais, cada indivíduo percebe o ambiente de forma particular, para van Lier, a percepção, a interpretação e a ação formam um ciclo contínuo e mútuo de reforço, ou seja, são pré-condições à emergência do significado (PAIVA, 2010) e, consequentemente, para a constatação da existência das affordances no meio.

Para identificação e discussão das affordances como auxiliares e/ou facilitadoras (ou não) no processo de aquisição da Libras como L2 por uma aprendiza ouvinte (sujeito de pesquisa), o estudo apresentado neste artigo fez uso da pesquisa narrativa (CONNELLY; CLANDININ, 1990; CLANDININ; CONNELLY, 2000; TELLES, 2002), de natureza interpretativista qualitativa (MOITA LOPES, 1994; BORTONI-RICARDO, 2008), que permite investigar a realidade reconstruída por meio de histórias de experiências pessoais, profissionais e pessoais. Dessa forma, subsidiada pelas oportunidades de reflexões provenientes da pesquisa narrativa, esta pesquisa fez uso (para análise, apresentação e discussão de resultados) de cinco narrativas e quatro notas mentais produzidas pelo sujeito desta pesquisa, correspondentes aos cinco primeiros anos (2010 a 2014) de contato e exposição da aprendiza à língua de sinais. Ainda, as narrativas e as notas mentais foram analisadas seguindo a tradição de pesquisa em linguística aplicada, no contexto da pesquisa interpretativista, que permite a utilização de um método não experimental, produzindo dados qualitativos por meio da análise interpretativa (GROTJAHN, 1987), que coloca a pesquisa em acordo com o grau em que o pesquisador pré-especifica o fenômeno investigado (NUNAN, 1992).

Assim sendo, esta pesquisa está respaldada na teoria das affordances de Gibson (1977), advinda da psicologia ecológica; bem como nos estudos de van Lier (2000, 2002, 2004) e Paiva (2010), também sob a perspectiva ecológica na área de aquisição de segunda língua. Com o objetivo de apresentar a temática estudada e discutir os resultados da pesquisa em questão, este artigo está organizado em cinco seções, além desta introdução, quais sejam: Língua brasileira de sinais - Libras, Affordances e aquisição de segunda língua, Metodologia de pesquisa, Análise dos dados e Considerações finais.

\section{Língua brasileira de sinais - Libras}

A Língua brasileira de sinais (Libras) é utilizada como primeira língua (L1) pela comunidade surda brasileira e adquirida como segunda língua (L2) pela comunidade ouvinte. A compreensão das regras de uma língua ocorre por meio do status linguístico que essa língua carrega; dessa forma, as línguas de sinais (viso-espacial), assim como as línguas orais (oralauditiva), apresentam parâmetros linguísticos próprios. A Libras é uma língua

[...] autônoma reconhecida pela linguística e está composta de todos os componentes pertinentes às línguas orais, como, por exemplo, gramática, semântica e outros elementos, preenchendo, assim, os requisitos científicos para ser considerada instrumento linguístico de poder e força. (STREIECHEN, 2013, p. 28).

No caso específico da língua de sinais, a configuração de seu status linguístico iniciou por volta da década de 1960, sendo a língua primeiramente observada pelo linguista Willian Stokoe que iniciou a apresentação dos parâmetros linguísticos que essa língua atualmente possui (GESSER, 2009). No início, Stokoe apresentou três parâmetros das línguas de sinais: configuração de mão $(\mathrm{CM})$, locação $(\mathrm{L})$ e/ou ponto de articulação $(\mathrm{PA})$ e movimento $(\mathrm{M})$. Com o aprofundamento dos estudos, identificou-se, ainda, mais um parâmetro, a orientação da palma da mão (O) (STREIECHEN, 2003). Além desses parâmetros, as línguas de sinais usam expressões faciais que também são conhecidas como marcadores não manuais (MNM). A seguir uma explicação resumida de cada um desses parâmetros:

Práxis Educativa, Ponta Grossa, v. 11, n. 2, p. 434-448, maio/ago. 2016 Disponível em: <http://www.revistas2.uepg.br/index.php/praxiseducativa > 
- CM: formas que as mãos realizam um sinal, equivalendo algumas ao alfabeto manual (datilológico). Até o momento, são setenta e cinco CM catalogadas.

- L e/ou PA: remete ao local onde é realizado o sinal, podendo ser articulada em uma parte do corpo ou em um espaço neutro.

- M: estabelece relação com as formas e as direções dos sinais. "O movimento que a(s) mão(s) desenvolve (m) no espaço ou sobre o corpo pode ser em linhas retas, curvas, sinuosas ou circulares em várias direções e posições" (BRITO, 1995 apud STREIECHEN, 2003, p. 44).

- O: direção da palma da mão no momento de realizar o sinal, sendo elas: para cima, para baixo, para o corpo, para frente, para a esquerda ou para a direita (STREIECHEN, 2003).

- MNM: Esse parâmetro é muito importante no momento de uma conversação, pois é por meio dele que se tem a entonação na língua de sinais. Movimentos da face e corpo que podem acompanhar os sinais estão subdivididos em: a) expressões faciais afetivas fazem referência aos sentimentos e às emoções - tristeza, alegria, medo, sono, assustado etc.; b) expressões faciais gramaticais fazem referência às sentenças e ocorrem simultaneamente aos sinais - afirmativa, negativa, exclamativa e interrogativa.

Em sua forma de manifestação linguístico-comunicativa, as línguas de sinais expressam-se por conceitos abstratos e conceitos concretos, representados por meio de sinais icônicos e sinais arbitrários, respectivamente. Os primeiros sinais (como em "árvore", "caneta" e "telefone") reproduzem, em suas sinalizações, a imagem do referente da palavra sinalizada, espelhando a realidade que representam. Os sinais icônicos, portanto, lembram de fato o objeto sinalizado, se associado ao movimento que o usuário da Libras faz perante o objeto, como, por exemplo, ao pegar o telefone e levar até o ouvido, ou ao apertar a caneta - movimentos simples e comuns para ouvintes também. Ainda, no exemplo da palavra "árvore", o que se sinaliza é o movimento que as folhas fazem em contato com o vento. No caso de usuários de línguas orais, esses sinais icônicos permitem aos ouvintes a facilidade na compreensão e na memorização, pois se trata de um conhecimento que já possuem internalizados em seu meio social, via aquisição de sua L1. Os segundos sinais (como em "mês", "educação" e "médico") não reproduzem o que foi sinalizado, ou seja, não se assemelham à realidade que representam. Dessa forma, os sinais abstratos não fazem nenhuma analogia entre signo e significante, podendo ser um fator de dificuldade na compreensão e na memorização da Libras pelos usuários de línguas orais, pelo fato de esses sinais não serem efetivos na comunidade de ouvintes.

Do ponto de vista do usuário das línguas de sinais, Fernandes (2012, p. 40) destaca como o sujeito surdo aprende e interage com o meio, considerando que a "[...] linguagem se constitui na integração com outros sujeitos e, que para tanto, não basta ensiná-la ao surdo, é necessário inserilo em um diálogo, para que, por meio do processo de interação/ interlocução, possa chegar à construção de significados".

Por fim, salientamos que as línguas de sinais não são universais. Cada país possui sua própria língua de sinais, assim como possui uma língua oral. No caso do Brasil, a língua portuguesa (ou língua brasileira) é a língua oral oficial, sendo a Libras a língua de sinais oficial. Ainda, da mesma forma como acontece nas línguas orais, cada estado brasileiro possui variações linguísticas da Libras. Nesse panorama, a Lei 10.436/2002, regulamentada pelo Decreto 5.626/2005, oficializou a Libras no Brasil, garantindo à comunidade surda o direito à cidadania. A partir de então, a Libras é uma língua co-ofical do Brasil.

Práxis Educativa, Ponta Grossa, v. 11, n. 2, p. 434-448, maio/ago. 2016 Disponível em: <http://www.revistas2.uepg.br/index.php/praxiseducativa > 


\section{Affordances e aquisição de segunda língua}

Em dicionário de língua inglesa (SIMPSON; WEINER, 2015), o verbo afford descreve ações e funções como produzir, fornecer, dar, causar, proporcionar, conferir, oferecer, propiciar, ter os meios ou recursos para fazer ou adquirir algo. O substantivo affordance, por outro lado, cujo verbete não consta em dicionário, foi utilizado pela primeira vez pelo psicólogo norte-americano James Gibson, no contexto da percepção visual e inserido no que ele considerou como psicologia ecológica para descrever o que o ambiente oferece, propicia e/ou fornece ao animal, para o bem ou para o mal; bem como para delinear as relações do organismo com os elementos do ecossistema.

Segundo Gibson (1977), em sua teoria das affordances, o ambiente consiste em superfícies terrestres que separam as substancias do meio em que os animais vivem. Ao observador, essas superfícies proporcionam informações - em uma relação intrínseca entre superfície e affordance no processamento psicológico da percepção do ecossistema; ou seja, ao perceber as superfícies que lhe são externas, o observador percebe o que elas lhe oferecem (e/ou podem oferecer) em termos de "valores" e "significados" presentes no ambiente, viabilizando ações e/ou interações, para o bem ou para o mal, com esse ambiente. Dessa forma, as affordances são tanto a complementaridade do ambiente quanto do animal (observador). Essa interação ambienteanimal, em diferentes superfícies e propiciadas pelo meio, faz emergir comportamentos diversos em diferentes animais via percepção (ou não) dos distintos arranjos e/ou mecanismos presentes nessas superfícies. As affordances

[...] são, de certa forma, objetivas, reais e físicas, ao contrário de valores e significados que, muitas vezes, são supostos de ser subjetivo, fenomenal e mental. Mas, na verdade, uma affordance não é uma propriedade objetiva ou subjetiva; ou é ambas se quiser. Uma affordance supera a dicotomia subjetivo-objetivo e nos ajuda a entender sua inadequação. É igualmente um fato do ambiente e um fato de comportamento. É tanto física como psíquica. Uma affordance aponta em ambos os sentidos, ao meio ambiente e ao observador $^{1}$. (GIBSON, 1977, p. 129).

Assim, a percepção de affordances não é um processo de perceber um objeto livre de valor físico ao qual, de alguma forma, significado é adicionado, mas é um processo de percepção de um objeto ecológico rico em valor, sendo a presença do observador (e de estímulos para a percepção) fundamental para que uma affordance tenha seu papel e valor na sociedade. Dentro dessa perspectiva, a concepção de affordance, conforme Gibson (1977), também está diretamente relacionada à noção de nicho ecológico. Para os ecologistas, nicho - que difere do conceito de habitat (local, lugar ou espaço físico onde o animal vive) - refere-se à forma, ao modo como o animal vive (modo de vida), o que sugere ser o nicho um conjunto de affordances em uma relação de complementaridade entre um (nicho) e outro (affordances).

Como sinalizado anteriormente, no contexto da psicologia ecológica de Gibson, o termo affordance visa superar a dicotomia subjetivo-objetivo. Também, na pedagogia linguística, o conceito de ecologia emerge para desfazer a dicotomia entre processos cognitivos (internos) e sociais (do ambiente). $\mathrm{Na}$ área específica de aquisição de segunda língua, na linguística aplicada, por exemplo, a abordagem ecológica tem contribuído "[...] para explicar como os usuários de línguas e os alunos interagem com seu ambiente ou contexto" (LARSEN-FREEMAN; CAMERON, 2008, p. 19) e fornecido mecanismos para suplantar a dicotomia input-output (listening-speaking). Segundo van Lier (2000, p. 258), "[...] educadores ecológicos veem a língua e a aprendizagem como relações entre os aprendizes e entre eles e o seu meio ambiente", o que "[...] não implica em negar os processos cognitivos e sociais, mas sim em criar uma conexão entre

\footnotetext{
${ }^{1}$ Essa e outras traduções neste artigo são de nossa inteira responsabilidade.
}

Práxis Educativa, Ponta Grossa, v. 11, n. 2, p. 434-448, maio/ago. 2016 Disponível em: <http://www.revistas2.uepg.br/index.php/praxiseducativa $>$ 
esses processos". Para o autor, uma visão ecológica de aprendizagem de língua é relacional e não material, ou seja, adquirir uma língua não é um processo linear de estoque de estruturas linguísticas no cérebro (imput) para a produção da fala (output). Nesse contexto, ainda de acordo com o autor, a concepção das affordances ajuda-nos a entender que o ambiente (o mundo linguístico do aprendiz) está cheio de linguagem, demandas, exigências, oportunidades, limitações, rejeições, convites, capacidades e restrições que, potencialmente, propiciam oportunidades para o aprendiz ser ativo, participante e autônomo no processo de aquisição da linguagem. Como acontece na psicologia ecológica, quando tratamos da aquisição de uma segunda língua e/ou língua adicional, o nicho é fundamental para que a aprendizagem ocorra, pois é em um determinado nicho dentro do ambiente, nesse caso a sociedade, que as interações acontecem. Ainda, as pessoas aprendem uma língua por vários motivos ou de várias formas, mas será em determinados nichos ou locais que a aquisição da língua irá fluir.

Van Lier (2004), ao refletir sobre o termo affordance no contexto de ensino, destaca suas principais definições como relações, possibilidade, oportunidade, imediatismo e interação. Logo, o autor acrescenta que affordance refere-se ao que está disponível à pessoa, já que não se constitui com uma propriedade do meio. Assim, a ação em potencial surge quando interagimos com o mundo físico e social. Nas práticas sociais, cada indivíduo percebe o ambiente de forma particular e há, também, a possibilidade de aprender-se a perceber o que o ambiente pode oferecer. Nessa interação, para van Lier, a percepção (perception), a interpretação (interpretation) e a ação (action) formam um ciclo contínuo, de reforço mútuo, que é uma pré-condição à emergência do significado ou do potencial significado ou, em outras palavras, da affordance, como mostra o esquema na Figura 1 a seguir.

Figura 1 - Affordance

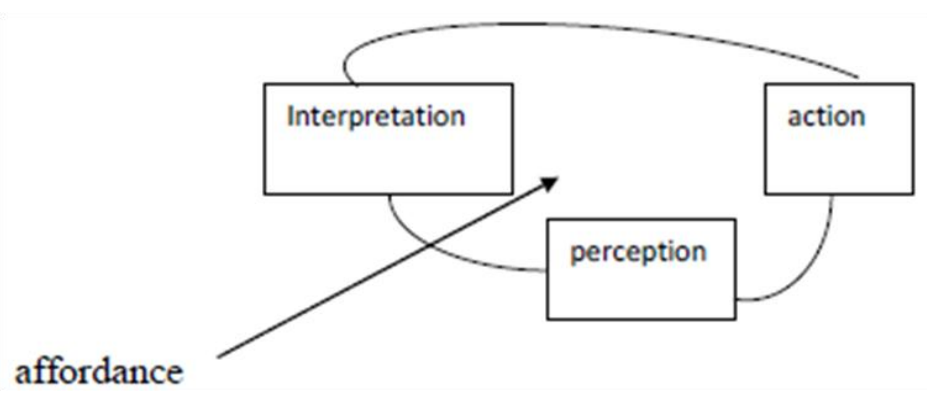

Fonte: Van Lier (2004, p. 92).

Seguindo a linha de reflexão de van Lier, Paiva (2010, p. 3) enfatiza que "[...] a ideia de que a percepção e a interpretação do ambiente propicia certas práticas sociais tem influenciado a forma como olhamos para o fenômeno aprendizagem de língua", tendo em vista que usamos a língua para agir, perceber e interpretar o mundo e as ações sociais da linguagem. O envolvimento na linguagem ocorre quando o conhecimento do indivíduo interage com o ambiente e este com a língua a que está exposto. Assim, as affordances oferecem oportunidades de aprendizagem. Ziglari (2008), também no contexto de aquisição de segunda língua, foca na questão do emergentismo, uma abordagem cognitiva que enfatiza a interação organismo-ambiente e rejeita a noção de capacidades pré-determinadas. $\mathrm{O}$ emergentismo surge do resultado da interação com o meio ambiente, o que pode causar variações na quantidade de aprendizagem conforme as diferentes experiências que são propiciadas por diferentes affordances. No contexto do ensino formal, Paiva (2010) argumenta que se deve reconhecer que as escolas sozinhas não dão conta de reunir todas as affordances necessárias para o desenvolvimento da linguagem e, ao mesmo tempo, abrir os olhos 
de nossos alunos para o mundo, o que exige dos aprendizes uma autonomia em relação ao despertar para as affordances disponíveis. A autora ainda enfatiza, destacando o trabalho de van Lier, que aprendemos a linguagem da mesma forma que um animal "aprende" a floresta. Assim, o papel do professor é no sentido de ajudar os alunos a ocuparem seus nichos, usando as línguas que estão aprendendo.

\section{Metodologia de pesquisa}

A questão central desta pesquisa foi diagnosticar o papel das affordances no processo de primeiro contato e de aquisição da Libras (língua viso-espacial), como L2, por uma aprendiza ouvinte (cuja L1 é a língua brasileira, oral-auditiva), no período de cinco anos (2010 a 2014). As perguntas de pesquisa que nortearam o estudo foram as seguintes: Quais affordances impulsionaram a aquisição da Libras pela aprendiza ouvinte? Como a aprendiza ouvinte se desenvolveu com relação às affordances disponíveis no nicho? Quais foram as principais características que levaram a aprendiza ouvinte a inserir-se no ciclo de percepção, interpretação e ação - condição de emergência das affordances - dentro do nicho? As respostas às perguntas foram obtidas por meio da análise de cinco narrativas (uma para cada ano de contato da aprendiza ouvinte com a Libras) e quatro notas mentais complementares às três primeiras narrativas.

As cinco narrativas e quatro notas mentais foram produzidas ao longo do ano de 2014 , via escrita, pelo sujeito da pesquisa, e abrangem apenas eventos voltados à realidade, pois tratam de relatos de fatos reais na vida da aprendiza ouvinte em seu processo de primeiro contato e aquisição da Libras durante os anos de 2010 a 2014. Salienta-se que a aprendiza ouvinte e sujeito da pesquisa (doravante aprendiza) é também uma das pesquisadoras deste estudo. Como já destacado, o contexto de produção das narrativas e notas mentais abrange cinco anos (2010 a 2014), estando assim dispostos: 1) a narrativa 1 (N1) refere-se ao ano de 2010 e descreve o início do processo de contato da aprendiza com a Libras no Ensino Médio - as notas mentais 1 (NM1) e 2 (NM2), apesar de também narrarem os primeiros contatos da aprendiza com a Libras, referem-se a anos anteriores a 2010; 2) a narrativa 2 (N2) e a nota mental 3 (NM3) correspondem ao ano de 2011 e focam a questão do nicho no processo de aquisição da Libras; 3) a narrativa 3 (N3) e a nota mental 4 (NM4) aludem ao ano de 2012, destacando participações da aprendiza em eventos da comunidade surda; 4) a narrativa 4 (N4), ano de 2013, mostra o distanciamento da aprendiza ouvinte com a cultura surda - já iniciado ao final de 2012; 5) a quinta e última narrativa (N5), que correspondente ao ano de 2014, enfatiza o ingresso da aprendiza em curso de graduação.

Para a coleta de dados (produção das narrativas e notas mentais), utilizou-se dos recursos da introspecção (retroativa) no contexto da pesquisa narrativa (CLANDININ; CONNELY, 2000). No que tange a análise dos dados e a produção dos resultados, valeu-se da pesquisa interpretativista de natureza qualitativa (MOITA LOPES, 1994; BORTONI-RICARDO, 2008).

Segundo Moita Lopes (1994), a pesquisa interpretativista prevê o acesso indireto ao fato de pesquisa por meio da interpretação dos vários significados que o constituem. De acordo com Bortoni-Ricardo (2008, p. 32), o paradigma interpretativista surge como uma alternativa ao positivismo e tem por finalidade viabilizar a interpretação das ações sociais e o significado que as pessoas conferem a essas ações na vida social, salientando que "[...] não há como observar o mundo independente das práticas sociais e significadas vigentes". Nesse contexto, a capacidade de compreensão do observador (pesquisador) está enraizada em seus próprios significados e não no estabelecimento de relações entre causa e consequência entre os fenômenos. Esse é também o caráter da pesquisa qualitativa, que procura entender e interpretar fenômenos sociais inseridos em

Práxis Educativa, Ponta Grossa, v. 11, n. 2, p. 434-448, maio/ago. 2016 Disponível em: <http://www.revistas2.uepg.br/index.php/praxiseducativa $>$ 
um determinado contexto, ou seja, o pesquisador estará mais interessado no processo, buscando entender o como e o porquê dos resultados.

Conforme Clandinin e Connely (2000), a pesquisa narrativa visa abranger experiências e entendê-las por meio da produção (oral ou escrita) e da análise de histórias de vida reconstruídas (retroativamente), em um processo que se constitui entre o pesquisador e o pesquisado. Assim, esse tipo de pesquisa busca entender a experiência humana, vivenciada, e, dependo do momento abordado, pode corresponder a uma versão imutável. De acordo com Bruner (2002, p. 46), uma narrativa "[...] é composta por uma sequência singular de eventos, estados mentais, ocorrências envolvendo seres humanos como personagens ou autores". As narrativas geralmente iniciam-se de forma estável podendo se desestabilizar e voltar à estabilidade e podem tanto caracterizar-se em um evento "real" quanto em um evento "imaginário". A coleta das histórias de vida pode ser obtida por meio de várias formas: entrevistas, diários, autobiografias, gravação de narrativas orais, narrativas escritas e notas de campo. Gibbis (2009) salienta que as notas mentais, assim como as notas de campo, são utilizadas para registrar palavras, frases ou ações fundamentais concernentes aos sujeitos de pesquisa e/ou à situação de pesquisa.

\section{Análise dos dados}

Resultados importantes deste estudo interpretativista de natureza qualitativa (MOITA LOPES, 1994; BORTONI-RICARDO, 2008) estão relacionados à hipótese inicial de que as affordances (GIBSON, 1977) seriam um potencial elemento facilitador na aquisição da Libras como L2, principalmente em estágios iniciais desse processo. Partindo dessa hipótese central, as perguntas de pesquisa (dispostas no tópico sobre metodologia de pesquisa deste artigo) nortearam a análise do ciclo de percepção, de interpretação e de ação (VAN LIER, 2004) na emergência de significados (affordances) em cinco narrativas (N1, N2, N3, N4 e N5) e quatro notas mentais (NM1, NM2, NM3 e NM4) sobre a história de vida (de 2010 a 2014), concernente ao processo de primeiro contato e de aquisição da Libras como L2 da aprendiza ouvinte e sujeito desta pesquisa (de agora em diante apenas aprendiza). Para apresentação e discussão dos resultados expostos a seguir, as narrativas foram divididas em excertos (E) pelas pesquisadoras, usando apenas os mais significativos para o contexto da pesquisa, sendo as notas mentais, que completam as N1, N2 e N2, quando usadas, expostas na integra. A N1 foi recortada em oito excertos (E1, E2, E3, E4, E5, E6, E7 e E8), a N2 em três (E1, E2 e E3), a N3 em seis (E1, E2, E3, E4, E5 e E6), a N4 em quatro (E1, E2, E3 e E4) e a N5 em dois (E1 e E2).

Como já enfatizado, a N1 e as NM1 e 2 correspondem aos primeiros anos de contato da aprendiza com a Libras. No entanto, podemos perceber no E1 da N1 e na NM 1 e 2, dispostas a seguir, que, antes do ano de 2010 e do ingresso da aprendiza ao Ensino Médio - onde passa, de fato, a ter contato com os surdos ("na turma com quem passaria o ano todo, estava incluído seis surdos" (E1, N1)) -, a aprendiza ainda não conhecia a Libras, mas a visualização da comunicação via língua de sinais entre surdos, anos antes (primeiro, em uma multidão (NM1) e, depois, em um jogo de futebol de salão (NM2)), despertara-lhe a atenção para a língua ("Desde, então, senti vontade de conhecer mais aquela lingua(gem), até então desconhecida, que os surdos utilizavam para se comunicar" (E1, N1)), o que a leva a querer aprendê-la ("A curiosidade me instigou a aprender" (E1, N1)). Notamos aqui que o despertar para a Libras está subsidiado pela percepção das affordances ("sinais acima da aglomeração de pessoas" (NM1); "se comunicando através das mãos e corpo" (NM2)) provenientes do meio naqueles momentos específicos:

Práxis Educativa, Ponta Grossa, v. 11, n. 2, p. 434-448, maio/ago. 2016 Disponível em: <http://www.revistas2.uepg.br/index.php/praxiseducativa > 
[...] aos meus dez anos de idade houve men primeiro contato visual com sinais (visualizandol prestando atenção); pessoas conversando a longa distância executando/transmitindo os sinais acima da aglomeração de pessoas para chegar o entendimento até os amigos que estavam do outro lado. (NM1).

[...] mais uma vez vi pessoas se comunicando através das mãos e corpo, desta vez com quatorze anos. Porém, desta vezposso ter a certeza de que eram surdos se comunicando, estavam competindo, jogando uma partida de futsal, no colégio. (NM2).

Desde, então, senti vontade de conhecer mais aquela lingua(gem), até então desconhecida, que os surdos utilizavam para se comunicar. A curiosidade me instigou a aprender. Mas, a questão era como conseguir se comunicar, parecia que estava tão longe de aprender, e, após algum tempo, desvinculei dessa possibilidade de aprendizagem. Em 2010, fui para a cidade de Ivai - PR, cursar o Ensino Médio. Logo, no primeiro ano, na turma com quem passaria o ano todo, estavam incluidos seis surdos e a presença de uma intérprete em sala. (E1, N1).

Como podemos verificar no E1 da N1, a aprendiza inicia efetivamente o seu contato com os surdos ao ingressar no Ensino Médio no ano de 2010, momento em que passa a conviver com seis colegas de classe surdos e uma tradutora/intérprete de Libras. O fato de estudar com surdos em sala de aula e ainda ter contato com uma tradutora/intérprete proporcionou à aprendiza o contato direto com a Libras e com potenciais affordances (alunos surdos e intérprete, essencialmente) para a aquisição dessa língua de sinais. A partir desse momento, o interesse da Libras pela aprendiza, já iniciado anos antes, foi crescendo e a sua aquisição foi se efetivando em um processo contínuo, essencialmente via observação ("atenta para todo e qualquer movimento da intérprete" (N1, E2)) - sendo a observação um componente de suma importância para o desenvolvimento do ciclo percepção-interpretação-ação (VAN LIER, 2004) que subentende as affordances no meio. Nesse contexto, a aprendiza soube aproveitar a presença da intérprete para avançar seu conhecimento na língua de sinais, como podemos constatar nos E2, 5 e 6 da N1 a seguir:

No início, era algo novo, baseada em observações, atenta para todo e qualquer movimento da intérprete, pois é ela quem transmitia todo o conhecimento da professora para os alunos surdos. Depois de observar vieram alguns questionamentos, "por que assim e não de outra forma?" (aqui me refiro aos sinais, por que é feito dessa forma e não de outra), como uma criança que está conbecendo e questionando o mundo ao seu redor. (E2, N1).

Outro recurso utilizado era agrupar vocabulários, escrevendo uma palavra ou frase em uma folha, e então, os surdos respondiam/devolviam em sinais. Perguntar a intérprete também contribuiu para a aprendizagem da lingua, pois os surdos, às vezes, não compreendiam as palavras. (E5, N1).

Logo, para facilitar muita das sinalizacões, en recorria para sinônimos das palavras. Se tivesse a oportunidade de questionar a sinalização das palavras on sentenças, en recorria à intérprete, principalmente no inicio da aquisição da lingua, pois havia a necessidade de conbecer muito mais os sinais nesse momento. E a intérprete era fundamental para explicar termos, sinais, classificadores em Libras. Muitas vezes, a intérprete era a ponte para a comunicação entre surdos e ouvintes na sala de aula, em qualquer situação. (E6, N1).

O/A tradutor(a)/intérprete de língua de sinais possui uma importância muito grande na aprendizagem dos conhecimentos escolares para os surdos em contextos de inclusão nas escolas em que a língua majoritária é a oral-auditiva. Contudo, podemos perceber, também, em outras partes da N1 ("Perguntar a intérprete também contribuiu para a aprendizagem da língua" (E5); "Se tivesse a oportunidade de questionar a sinalização das palavras ou sentenças, eu recorria a intérprete, principalmente no início da aquisição da língua" (E6); "a intérprete era fundamental para explicar termos, sinais, classificadores em Libras" (E6); "a intérprete era a ponte para a comunicação entre surdos e ouvintes na sala de aula" (E6)), que a presença da intérprete ajudou muito na mediação Português-Libras entre alunos surdos e ouvintes em sala de aula, potencialmente contribuindo para a percepção das affordances tanto para a compreensão do

Práxis Educativa, Ponta Grossa, v. 11, n. 2, p. 434-448, maio/ago. 2016 Disponível em: <http://www.revistas2.uepg.br/index.php/praxiseducativa> 
português pelos surdos quanto para a compressão da Libras pelos ouvintes. Nesse contexto, a intérprete e os seis surdos compõem o nicho (conjunto de affordances) que emerge em sala de aula oportunizando o ciclo de percepção, de interpretação e de ação (VAN LIER, 2004) pela aprendiza. Esse nicho viabiliza, por um lado, uma rica interação entre os surdos, os ouvintes e a intérprete e, consequentemente, por outro lado, contribui para o desenvolvimento da Libras pela aprendiza. Ainda em relação ao nicho que emergiu em sala nesse contexto específico e que coopera para o processo de aquisição da Libras como L2 pela aprendiz, verificamos que, no E2 da N1 ("Depois de observar vieram alguns questionamentos, "por que assim e não de outra forma?"), as affordances que mais contribuíram para aquisição da Libras pela aprendiza estavam efetivadas no colégio, tendo em vista que a aprendiza narra que, depois das observações, vieram os questionamentos sobre os usos dos sinais. Questionamentos, por sua vez, de uma aprendiz em pleno desenvolvimento da Libras que se equipara a de "[...] uma criança que está conhecendo e questionando o mundo ao seu redor" (E2, N1). O fato de a aprendiza fazer parte desse nicho específico proporcionou a ela um salto qualitativo em sua autonomia para a aprendizagem da Libras ao permitir o desenvolvimento do ciclo percepção-interpretação-ação (VAN LIER, 2004) das affordances no meio. Esse fato poder ser verificado também em varias situações como no E6 da N1, por exemplo, quando a aprendiza recorre ao uso de palavras sinônimas por não saber a correspondência entre um sinal e sua palavra correspondente ("para facilitar muita das sinalizações eu recorria para sinônimos das palavras"). Nos E3 e 4 da N1, a seguir, a aprendiza, também por conta própria, avança em seus estudos sobre a Libras, aprendendo o máximo de palavras, sinais e o alfabeto manual para poder comunicar-se com os surdos.

\begin{abstract}
A primeira tentativa de uma conversa que tive com um surdo com uma frase de cumprimento: "Oi, tudo bem?", a partir desde momento o interesse pela lingua só aumentava, conhecer o maior número de palavras/sinais em Libras para, então, conseguir comunicar-se. (E3, N1).

Não demorou, aprender o alfabeto manual da Libras foi algo fácil e rápido, este aprendizado foi pelo livro didático do primeiro ano do Ensino Médio. $O$ "ABC" da Libras foi fundamental para meu aprendizado e desenvolvimento na Lingua de Sinais. Através do alfabeto manual en conseguia perguntar diretamente para os surdos, dando-lhes a palavra na forma datilologia, ou seja, manualmente escrita no espaço neutro, e logo em seguida o surdo devolvia o sinal correspondente à palavra. Ou, ainda, ocorria o inverso, eu perguntava que sinal era aquele, feito pelo surdo que até então não conhecia, e me respondiam com a palavra manualmente. (E4, N1).
\end{abstract}

Ainda, a autonomia da aprendiza em estudar a Libras, que emerge desse nicho, proporciona-lhe uma rápida assimilação - via estudo do livro didático (outro affordance), utilizado pela turma da Ensino Médio da qual ela fazia parte - do alfabeto manual da Libras ("aprender o alfabeto manual da Libras foi algo fácil e rápido" (E4, N1)), permitindo-lhe também estabelecer uma relação direta com os surdos no início da sua aquisição. Esse contato aproximado com os surdos, aumentando o interesse da aprendiza pela Libras, levou-a a estabelecer uma relação com a comunidade surda que foi muito além da escola, abrangendo questões da identidade e da cultura surda ("iniciava ali uma participação mais próxima com a comunidade surda no geral, envolvendo história, cultura e identidade" (E8, N1)), proporcionadas por sua participação em encontros regionais com os surdos (E8, N1; E5, N3) e sua organização (E3, N2) nos anos de 2010, 2011 e 2012; bem como a conduziu ao interesse na realização de cursos com foco na Libras nos anos de 2012 a 2013 (E4, N3; E4, N4) e envolvimento em programas, já cursando a universidade, em 2014, que viabilizassem pesquisa em Libras (E2, N5). Esses novos caminhos de contato com a Libras também podem ser considerados como affordances no processo de aquisição da Libras pela aprendiza.

Ainda em 2010, participei pela primeira vez. de um encontro de surdos regional o qual foi realizado na cidade de Guamiranga-PR. Esse foi o primeiro contato com a comunidade surda que iniciava ali uma participação mais próxima com a comunidade surda no geral, envolvendo história, cultura e identidade. (E8, N1).

Práxis Educativa, Ponta Grossa, v. 11, n. 2, p. 434-448, maio/ago. 2016 Disponível em: <http://www.revistas2.uepg.br/index.php/praxiseducativa $>$ 
Em 2011, não participei efetivamente do encontro regional, organizado em Ivai - PR. Porém, tive a oportunidade de ajudar a organizar o evento, nós ouvintes tínhamos planejado um teatro para apresentar neste mesmo encontro. Por questões temporais não apresentamos no dia. Mas a importância da colaboração para o evento ocorrer, foi essencial. (E3, N2).

[em 2012] (...) fui para mais um encontro regional de surdos, comemorando o mês azul, o dia do surdo em 26 de setembro, desta vez realizada em Irati - PR. (E5, N3).

[em 2012] O curso de Pós-Graduação que foi trazido à cidade era 'Educação Especial com Ênfase em Tradução e Interpretação de Libras', através da CENSUPEG. Esse, então, foi o meu primeiro estudo e pesquisa realizada da área da Lingua Brasileira de Sinais - LIBRAS. (E4, N3).

A Pós-Graduação terminara em outubro/novembro de 2013. Mesmo terminando nesse periodo, minha pesquisa continuava em andamento. (E4, N4).

[2014] Hoje continuo meus estudos, minhas pesquisas na área de Libras, participando do PIBIC pela UEPG. Notamos a importância de novas pesquisas realizadas na área da comunidade surda, do ponto de vista geral. Há poucas pesquisas voltadas para essa língua, área. (E2, N5).

Outra questão de suma importância diagnosticada na análise das narrativas foi a importância dos sinais icônicos na aquisição da Libras pela aprendiza, como se pode verificar no E7 da N1 a seguir.

Há dois grupos grandes em libras: os sinais icônicos e os sinais arbitrários. Esses sinais se agregaram ao longo de todos os anos da minha aprendizagem. Hoje posso verificar o quanto os sinais iconicos, sinais parecidos ou/e lembra os objetos/animais, me ajudaram na aquisição da lingua de sinais, pois era algo sempre voltado ao meu conhecimento prévio de mundo sobre o objeto/animal com relação ao sinal realizado, da lingua oral. (E7, N1).

Como já antecipado em outros momentos neste artigo, as línguas de sinais (assim como as línguas orais) expressam conceitos concretos e abstratos, compartilhando do princípio da arbitrariedade do signo linguístico saussuriano na relação entre significante e significado. Dessa forma, a Libras constitui-se de sinais icônicos e arbitrários. O primeiro é usado para expressar palavras como "telefone", "caneta", "árvore" que reproduzem a exata imagem do seu referente. O segundo é empregado para expressar vocábulos como "mês", "educação", "profissional" que não se assemelham à realidade que representam. Nesse contexto e considerando o aspecto visoespacial como o canal que permite a expressividade e/ou manifestação linguístico-comunicativa das línguas de sinais, tanto os sinais icônicos quanto os arbitrários podem também ser considerados como affordances no processo de aquisição das línguas de sinais, tanto para surdos (como L1) quanto para ouvintes (como L2). No entanto, os sinais icônicos, pelo espelhamento em sua expressão com o seu referente, convertem-se em uma affordance importante para os falantes de línguas orais em fases iniciais do processo de aquisição da língua de sinais ("Hoje posso verificar o quanto os sinais icônicos [...] me ajudaram na aquisição da língua de sinais" (E7, N1)). Isso devido à aproximação que se estabelece - via viso-espacial (sinais expostos externamente ao sujeito e percebidos concretamente no ambiente) - entre os mesmos referentes dos sinais icônicos das palavras sinalizadas e oralizadas, fazendo com que o aprendiz/a aprendiza de uma língua de sinais como L2 recorra ao conhecimento já adquirido de sua L1, como o fez a aprendiza aqui pesquisada ("era algo sempre voltado ao meu conhecimento prévio de mundo sobre o objeto/ animal com relação ao sinal realizado, da língua oral” (E7, N1)).

Ao avançar no estudo dos dados, podemos notar ainda a importância concreta do nicho para o processo de aquisição da Libras pela aprendiza; sendo, no contexto da perspectiva da psicologia ecológica de Gibson (1979), nicho (modo de vida) considerado como um conjunto de affordances em um determinado ambiente. Em contraste ao que é descrito na N1 e NM1 e 2, ano de 2010, - em que pudemos verificar a inserção da aprendiza em um rico nicho para a aquisição da Libras, proporcionado pela convivência dela em sala de aula do Ensino Médio com seis surdos

Práxis Educativa, Ponta Grossa, v. 11, n. 2, p. 434-448, maio/ago. 2016 Disponível em: <http://www.revistas2.uepg.br/index.php/praxiseducativa $>$ 
e uma intérprete. A partir da N2 e da NM3 (até a N5), ano de 2011 até 2014, há uma queda no processo de aquisição da Libras ("percebi que estava com algumas dificuldades para retomar o ritmo da sinalização" (E1, N2); "não ocorria o aprendizado da Libras como nos anos anteriores" $(\mathrm{E} 2, \mathrm{~N} 4))$ pelo afastamento da aprendiza com o nicho em que se encontrava, tendo em vista as férias escolares, em 2011, e o término dos estudos no Ensino Médio no final de 2012 (conforme pode-se observar na NM3 e no E1 da N2 e E2 da N4, a seguir). Isso devido ao fato de que o conjunto de affordances que permeavam o aprendizado da Libras como L2 pela aprendiza estava concentrado no nicho que emergiu em sala de aula do Ensino Médio.

\begin{abstract}
Quando entramos de férias do final de ano [2011], eu não mantive contato com os surdos, então, fiquei sem sinalizar durante dois meses (periodo de férias). Quando retornei ao colégio [2011], onde encontrava meus amigos surdos, tive que obter uma rápida retomada do que aprendi no ano anterior. Pois, é o contato com os surdos que instiga minha aprendizagem e fluência na lingua de sinais. (NM3).

No início do segundo ano [2011], percebi que estava com algumas dificuldades para retomar o ritmo da sinalização, pois já faz̧ia dois meses sem contato. Levou entre 15 dias a 30 dias para retomar as coisas já aprendidas durante o primeiro ano. Apenas necessitava de um feedback e do contato direto com os surdos, portanto com a Libras. (E1, N2).

Iniciei uma nova fase da minha vida, uma graduação [2013] [...] Porém, na universidade em que ingressei não havia surdos, por esse motivo não mantive contato direto com a Libras e com surdos. Dessa forma, não ocorria o aprendizado de Libras como nos anos anteriores, presente no colégio. (E2, N4).
\end{abstract}

Ao finalizarmos a análise das narrativas e das notas mentais, pontuando as questões que emergiram como mais relevantes para a discussão da temática do papel das affordances no processo inicial de aquisição da Libras como L2 por uma aprendiza ouvinte, retomamos as perguntas de pesquisa que nortearam o estudo na tentativa de respondê-las, como segue:

Quais affordances impulsionaram a aquisição da Libras pela aprendiza ouvinte? Entendemos que as affordances mais importantes foram: (1) inicialmente (antes de 2010), os sinais produzidos pelos surdos ao se comunicarem em uma aglomeração de pessoas despertando a curiosidade pela Libras por parte da aprendiza; (2) no ano letivo de 2011, os seis surdos e a tradutora/intérprete presentes na sala de aula do Ensino Médio em que a aprendiza fazia parte, emergindo dali um nicho (conjunto de affordances) importante para a viabilização do ciclo percepção, interpretação e ação (VAN LIER, 2004), pré-condições a emergências de significados no contexto das affordances. Ainda, o ano de 2011 mostra ser um momento de avanços importantes na aquisição da Libras pela aprendiza e no desenvolvimento de sua autonomia para a aprendizagem da língua de sinais, estimulando, também, a inserção da aprendiza na comunidade e na cultura surda em eventos voltados a esse público; (3) os sinais icônicos que, ao aproximarem as similaridades de significado das palavras sinalizadas e oralizadas, proporcionaram à aprendiza a possibilidade de recorrer ao conhecimento já adquirido em sua L1.

Como a aprendiza ouvinte se desenvolveu com relação às affordances disponíveis no nicho? A aprendiza mostrou um percurso interessante durante os anos de 2010 a 2014 em que se pode observar a importância do nicho que emergiu durante sua permanência no Ensino Médio, nos anos de 2010 a 2012 (com a presença de seis surdos e uma tradutora/intérprete), para um avanço importante de seu processo de aquisição da Libras e de sua autonomia em relação a esse processo. Já a partir de 2013, quando a aprendiza termina o Ensino Médio e ingressa na universidade, ela se afasta desse rico nicho o que ocasiona uma queda no processo de aquisição da Libras. Todavia, a aprendiza continua focada em buscar recursos que a mantenha inserida no universo da Libras, o que prova que sua autonomia para a aprendizagem da língua de sinais ainda se mantém viva. Em todo esse processo, podemos afirmar que a aprendiza se desenvolveu muito

Práxis Educativa, Ponta Grossa, v. 11, n. 2, p. 434-448, maio/ago. 2016 Disponível em: <http://www.revistas2.uepg.br/index.php/praxiseducativa > 
bem em relação às affordances disponíveis no nicho, aproveitando-as ao máximo para a aquisição da Libras.

Quais foram as principais características que levaram a aprendiza ouvinte a inserir-se no ciclo de percepção, de interpretação e de ação - condição de emergência das affordances - dentro do nicho? Nesse aspecto pensamos ser a riqueza do nicho (conjunto de affordances) em si que emergiu no contexto do Ensino Médio, de 2010 a 2012, que impulsionou o desenvolvimento do ciclo de percepção, interpretação e ação em relação ao meio para o processo de aquisição da Libras pela aprendiza. No entanto, o despertar para o conhecimento da Libras anos antes, em que a aprendiza, sem conhecer a língua de sinais, se sentiu instigada a conhecê-la - devido a sua percepção das affordances no meio naquele momento -, foi um gatilho importante para todo o processo de percepção, de interpretação e de ação em relação a todas as affordances que se revelaram para ela nos anos seguintes.

\section{Considerações finais}

A Libras é uma língua de sinais viso-espacial que depende muito mais do meio para o processo de percepção de interpretação visual de imagens e/ou sinalizações (do que as línguas orais) para ações e interações necessárias à sua expressividade linguístico-comunicativa. Por conseguinte, é uma língua que requer de seu usuário a observação do meio para poder agir sobre ele, via linguagem. As affordances (propriedades do ambiente que viabilizam ações psicologicamente possíveis) presentes no meio social, nos nichos (conjunto de affordances), impulsionam sua aquisição e/ou desenvolvimento. Dessa forma, a aquisição da Libras como L2 também consiste bastante em observar o meio para poder agir sobre ele; e focar nas informações que o meio social possui pode favorecer nessa aquisição, uma vez que as affordances estão presentes em todas as instâncias.

No âmbito da pesquisa aqui desenvolvida, os sinais icônicos da Libras, em nossa interpretação, emergiram com uma das affordances mais importantes para o processo de primeiro contato e de aquisição da Libras como L2 pela aprendiza ouvinte e sujeito da pesquisa, ao aproximarem significados das palavras sinalizadas (Libras) e oralizadas (português), proporcionando a possibilidade de recorrer ao conhecimento já adquirido pela aprendiza em sua L1. Por outro lado, a riqueza do nicho (conjunto de affordances) que emergiu no Ensino Médio ao conviver em sala de aula com seis surdos e uma tradutora/intérprete, bem como a permanência nele, durante três anos, mostrou-se fundamental para esse processo.

Essas foram questões tratadas e apresentadas por esta pesquisa e que podem ajudar no processo de ensino e de aprendizagem da Libras como L2 em diferentes contextos da educação formal, seja para conscientizar os aprendizes/as aprendizas sobre a importância das affordances que o ambiente pode lhes proporcionar - contribuindo para o desenvolvimento da autonomia para a aprendizagem da língua -; seja para sensibilizar professores de Libras como L2 para a necessidade da emergência e/ou da percepção de nichos potencialmente ricos em sala de aula e que sejam proveitosos para os/as alunos/as no processo de aquisição.

\section{Referências}

BORTONI-RICARDO, S. M. O professor pesquisador: introdução à pesquisa qualitativa. São Paulo: Parábola, 2008.

BRUNER, J. Atos de significação. 2. ed. Tradução Sandra Costa. São Paulo: Artmed, 2002.

Práxis Educativa, Ponta Grossa, v. 11, n. 2, p. 434-448, maio/ago. 2016 Disponível em: <http://www.revistas2.uepg.br/index.php/praxiseducativa $>$ 
CLANDININ, D. J.; CONNELLY, F. M. Narrative inquiry. New York: Teachers College Press, 2000.

CONNELLY, F. M.; CLANDININ, D. J. Stories of experience and narrative inquiry. Educational Researcher, v. 19, n. 5, p. 2-14, 1990.

FERNANDES, S. Educação de surdos. Curitiba: Ibepex, 2012.

GESSER, A. Libras? Que língua é essa? Crenças e preconceitos em torno da língua de sinais e da realidade surda. São Paulo: Parábola, 2009.

GIBBS, G. Análise de dados qualitativos. Tradução de Roberto Cataldo Costa. Porto Alegre: Artmed, 2009.

GIBSON, J. J. The theory of affordances. In: SHAW, R.; BRANSFORD, J. (Eds.). Perceiving, acting, and knowing: toward an ecological psychology. Hillsdale, NJ: Lawrence Erlbaum Associates, 1977. p. 67-82.

GROTJAHN, R. On the methodological basis of introspective methods. In: FAERCH, C.; KASPER, G. (Eds.). Introspection in second language research. Clevedon Avon, England: Multilingual Matters, 1987. p. 5-23.

LARSEN-FREEMAN, D.; CAMERON, L. Complex systems and applied linguistics. Oxford: Oxford University Press, 2008.

MOITA LOPES, L. P. Pesquisa interpretativista em linguística aplicada: a linguagem como condição e solução. D.E.L.T.A, São Paulo, v. 10, n. 2, p. 329-338, 1994.

NUNAN, D. Research methods in language learning. United States of America: Cambridge University Press, 1992.

ORLANDI, E. P. A língua brasileira. Ciência e Cultura, Campinas, v. 57, n. 2, p. 29-30, 2005.

PAIVA, V. L. M. Propiciamento (affordance) e autonomia na aprendizagem de lingual inglesa. In: LIMA, D. C. Aprendizagem de língua inglesa: histórias refletidas. Vitória da Conquista: UESB, 2010. p. 151-161.

SIMPSON, J.; WEINER, E. (Eds). The Oxford English Dictionary. 2. ed. Oxford: Claredon Press, 2015.

STREIECHEN, E. M. Libras: Aprender está em suas mãos. Curitiba: CRV, 2013.

TELLES, J. A. A trajetória narrativa. In: GIMENEZ, T. (Org.). Trajetórias na formação do professor de línguas. Londrina: Editora da Universidade Estadual de Londrina, 2002. p. 15-38.

VAN LIER, L. From input to affordance: social-interactive learning from an ecological perspective. In: LANTOLF, J. P. (Ed.). Sociocultural theory and second language learning. Oxford: Oxford University Press, 2000. p. 245-285. 
VAN LIER, L. An ecological-semiotic perspective on language and linguistics. In: KRAMSCH. C. (Org.) Language acquisition and language socialization: ecological perspectives. New York: Continuum, 2002. p. 140-164.

VAN LIER, L. The ecology and semiotics of language learning: A sociocultural perspective. Boston: Kluwer Academic Publishers, 2004.

ZIGLARI, L. Affordance and second language acquisition. European Journal of Scientific Research, v. 23, n. 3, p. 373-379, 2008.

Recebido em 07/12/2015

Versão corrigida recebida em 19/01/2016

Aceito em 05/03/2016 